\section{International Scientific Journal Theoretical \& Applied Science}

\author{
p-ISSN: 2308-4944 (print) e-ISSN: 2409-0085 (online) \\ Year: $2018 \quad$ Issue: $03 \quad$ Volume: 59
}

Published: $30.03 .2018 \quad$ http://T-Science.org
Shokhrat Izzat Alieva doctoral candidate of the department "Organization and management of business" of Sumgait State University, Sumgait, Azerbaijan Republic

SECTION 31. Economic research, finance, innovation, risk management.

\title{
MAIN DIRECTIONS OF THE SPECIALIZATION OF ENTERPRISE IN THE REGION OF AZERBAIJAN SHEKI-ZAKATALA IN MODERN CONDITIONS
}

\begin{abstract}
In the article actual problems and the main directions of the specialization of the enterprise of the region Sheki-Zagatala of Azerbaijan in modern conditions are considered. The economic potential and real conditions for ensuring the specialization of the enterprise for various types of activities are analyzed. The potential of certain spheres of agriculture and the agricultural sector has been revealed, which has great potential for the specialization of the enterprise. The expediency of specialization in grain and grain crops, silkworm breeding, tobacco growing, hazelnuts and tourism is substantiated. Generalized and given a number of recommendations and proposals on the main areas of specialization of the enterprise of the Sheki-Zagatala region of Azerbaijan in conditions of growing global influences.

Key words: Azerbaijan, the Sheki-Zagatala region, the Sheki-Zagatala economic region, the specialization of the enterprises in Sheki-Zagatala, the main areas of specialization the enterprises of Sheki-Zagatala.

Language: Russian

Citation: Alieva SI (2018) MAIN DIRECTIONS OF THE SPECIALIZATION OF ENTERPRISE IN THE REGION OF AZERBAIJAN SHEKI-ZAKATALA IN MODERN CONDITIONS. ISJ Theoretical \& Applied Science, 03 (59): 281-289.

Soi: http://s-o-i.org/1.1/TAS-03-59-48 Doi: crossef https://dx.doi.org/10.15863/TAS.2018.03.59.48

\section{ОСНОВНЫЕ НАПРАВЛЕНИЯ СПЕЦИАЛИЗАЦИИ ПРЕДПРИЯТИИ РЕГИОНА ШЕКИ- ЗАКАТАЛА АЗЕРБАЙДЖАНА В СОВРЕМЕННЫХ УСЛОВИЯХ}

Аннотация: В статье рассмотрены актуальные проблемы и основные направления специализации предприятии региона Шеки-Закатала Азербайджана в современных условиях. Анализированы экономические потенциал и реальные условия по обеспечению специализации предприятия по разным видам деятельности. Раскрыто потенциил отдельных сфер сельского хозяйство и аграрного сектора, которое имеет огромный потенциил для специиализации предприятия. Обосновано цчелесообразность специализации по зерно и зерновым культурам, шелководству, табаководству, фундуководство и туризму. Обобщень и даны ряд рекомендациий и предложений по основным направлениям специиализации предприятии региона Шеки-Закатала Азербайджана в условиях роста глобальных влияний

Ключевые слова: Азербайджан, регион Шеки-Закатала, экономический район Шеки-Закатала, специиализации предприятий Шеки-Закатала, основные направления специиализаџчии предприятий ШекиЗакатала
\end{abstract}

\section{Introduction}

В условиях глобализации экономических процессов в Азербайджане проводиться целенаправленные работы по диверсификации национальной экономики с учетом минимизации доли нефтяного сектора в нем и расширение деятельности ненефтяных секторов экономики страны. С этой целью разработано и осуществляется стратегические программы, которые охватывают все основные направления деятельности национальной экономики и в том числе развития регионов страны [1;2;3;4;5]. Одной из важных и стратегических направлений государственной социально-экономической политики считается сбалансированное развитие регионов страны с уклоном минимизации диспропорции между регионами. Проводиться полномасштабные работы по эффективному 


\begin{tabular}{|c|c|c|c|c|c|c|}
\hline Impact Factor: & $\begin{array}{l}\text { ISRA (India) } \\
\text { ISI (Dubai, UAE } \\
\text { GIF (Australia) } \\
\text { JIF }\end{array}$ & $\begin{array}{r}=1.344 \\
=0.829 \\
=0.564 \\
=1.500\end{array}$ & $\begin{array}{l}\text { SIS (USA) } \\
\text { PИHЦ (Russia) } \\
\text { ESJI (KZ) } \\
\text { SJIF (Morocco) }\end{array}$ & $\begin{array}{l}=0.912 \\
=0.207 \\
=4.102 \\
=\mathbf{2 . 0 3 1}\end{array}$ & $\begin{array}{l}\text { ICV (Poland) } \\
\text { PIF (India) } \\
\text { IBI (India) }\end{array}$ & $\begin{array}{l}=6.630 \\
=1.940 \\
=4.260\end{array}$ \\
\hline
\end{tabular}

использованию природных и экономических ресурсов регионов, рациональное размещение производительных сил, развитие предпринимательство, особенно традиционные сферы занятости - животноводство и растениеводство. С этой точки зрения особое значение имеет специализация регионов страны исходя из экономических потенциалов и возможностей данных регионов.

Materials and Methods
Отметим, что одной из инвестиционно привлекательного экономического региона страны является экономический район ШекиЗакатала, которое охватывает пять районов страны и одного города республиканского подчинения: г. Шеки, районы: Балакен, Гах, Огуз, Закатала и Габала [6].

На состоянии 01.01.2017-го года в экономическом районе Шеки-Закатала проживает около 612 тыс. человек.

На Рисунке 1 даны динамика численности населения в экономическом районе ШекиЗакатала, за 2010-2016 годы.

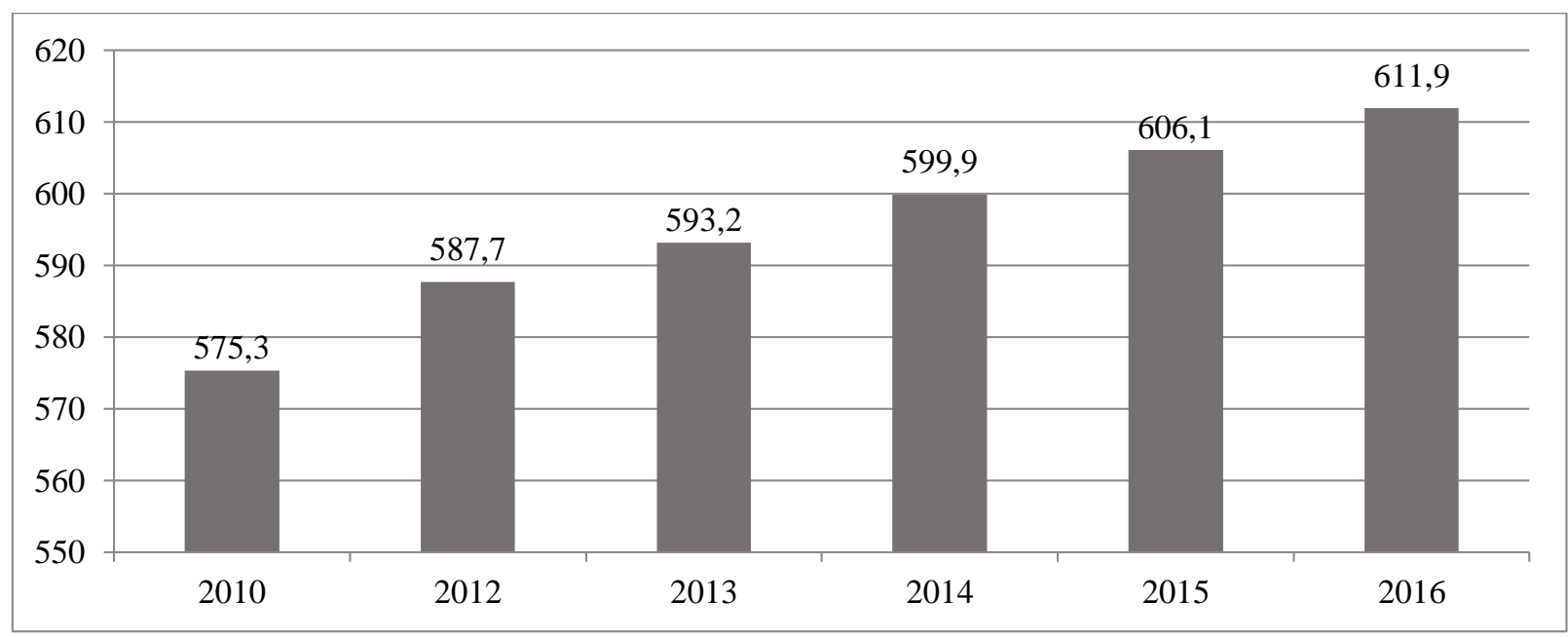

Рисунок 1. Динамика численности населения в экономическом районе Шеки-Закатала, тыс. чел., на конец года (подготовлено автором на основе материалов Государственного Статистического Комитета Азербайджанской Республики. www.stat.gov.az).

Как видно, по Рисунку 1 за 2010-2016 годы рост населения в регионе составило $6,4 \%$ и это свидетельствует о потенциале роста трудовых и человеческих ресурсов.
На Рисунке 2 дано динамика чисел работающих по контракту в разных сферах экономики региона Шеки-Закатала.

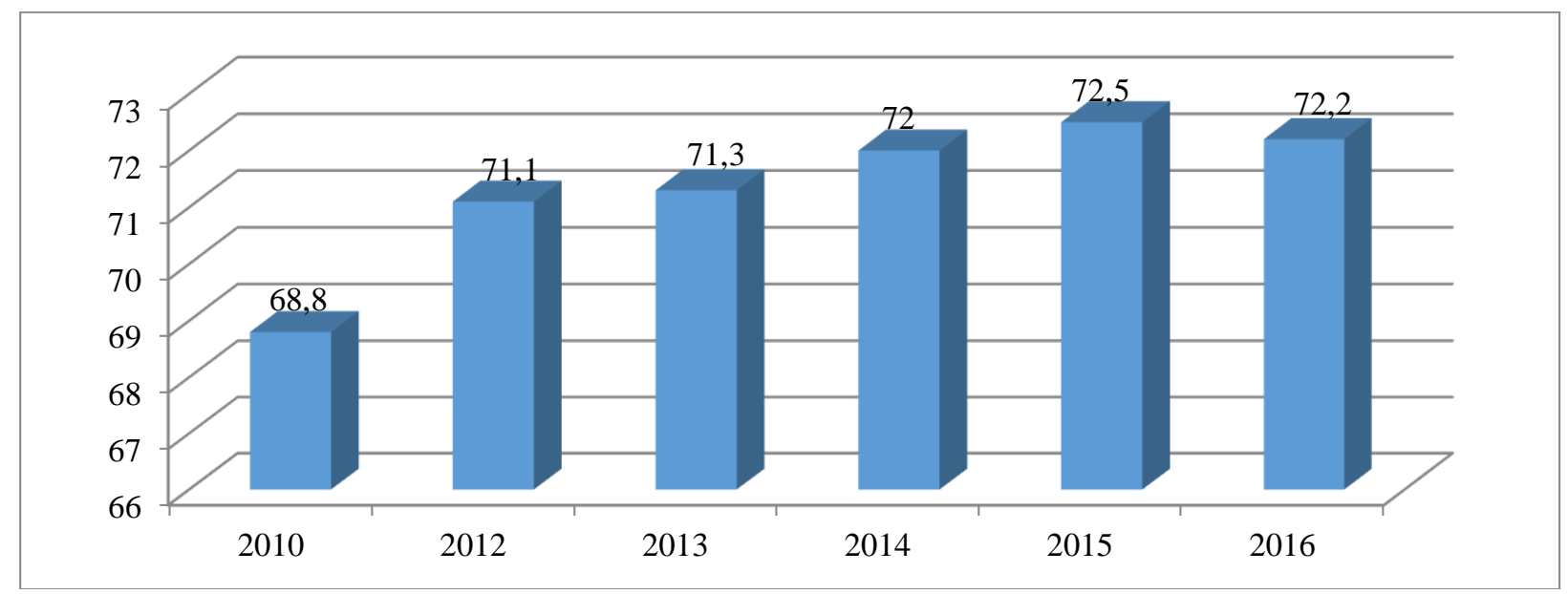

Рисунок 2. Динамика чисел работающих по контракту в разных сферах экономики региона ШекиЗакатала, тыс. чел. (подготовлено автором на основе материалов Государственного Статистического Комитета Азербайджанской Республики. www.stat.gov.az). 


\begin{tabular}{|c|c|c|c|c|c|c|}
\hline Impact Factor: & $\begin{array}{l}\text { ISRA (India) } \\
\text { ISI (Dubai, UAE } \\
\text { GIF (Australia) } \\
\text { JIF }\end{array}$ & $\begin{array}{r}=1.344 \\
=0.829 \\
=0.564 \\
=1.500\end{array}$ & $\begin{array}{l}\text { SIS (USA) } \\
\text { PИHЦ (Russia) } \\
\text { ESJI (KZ) } \\
\text { SJIF (Morocco) }\end{array}$ & $\begin{array}{l}=0.912 \\
=0.207 \\
=4.102 \\
=\mathbf{2 . 0 3 1}\end{array}$ & $\begin{array}{l}\text { ICV (Poland) } \\
\text { PIF (India) } \\
\text { IBI (India) }\end{array}$ & $\begin{array}{l}=6.630 \\
=1.940 \\
=4.260\end{array}$ \\
\hline
\end{tabular}

За 2010-2016 годы число работающих по контракту в разных сферах экономики региона Шеки-Закатала вырос на 3,4 тыс. человек и по итогом 2016 года составило 72,2 тыс. человек. В регионе активно создаются новые рабочие места, строятся современные конкурентоспособные предприятия по разным сферам, особенно по агропромышленному комплексу [7;8;9].

На Рисунке 3 отражено динамика числа гостиницы и аналогичных предприятий региона Шеки-Закатала, который является одной из основных туристических регионов страны [10].

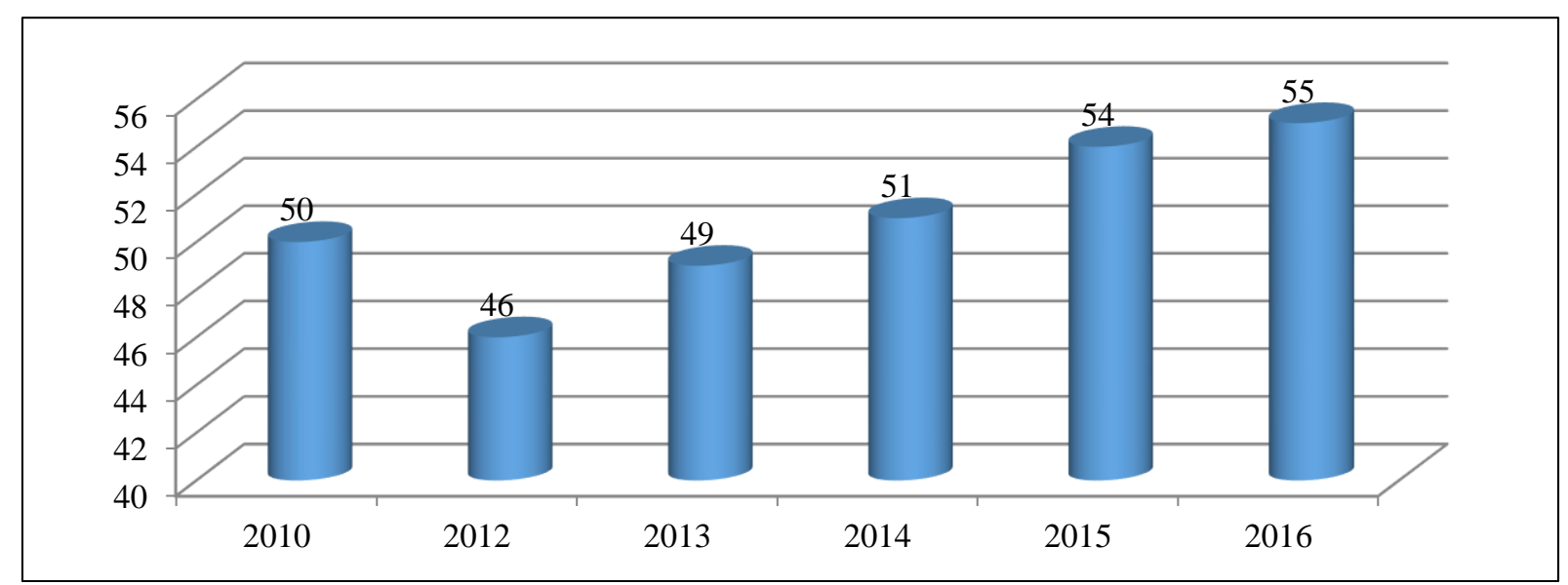

Рисунок 3. Динамика числа гостиницы и аналогичных предприятий региона Шеки-Закатала, единицы (подготовлено автором на основе материалов Государственного Статистического Комитета Азербайджанской Республики. www.stat.gov.az).

Отметим, что экономический район ШекиЗакатала является одним из основных сельскохозяйственным и агропромышленным центром страны, где в основном специализируется выращивание и производство ценных зерновых культур, продукции агропромышленных и бахчевых культур [11]. В регионе имеется все природные, географические и экономические ресурсы для интенсификации и специализации данных отраслей, с увеличением объема производства [12;13;14;15].

На Рисунке 4 дано объем пахотных участков по зерну и зерновых культур, в том числе пшеница в регионе Шеки-Закатала.

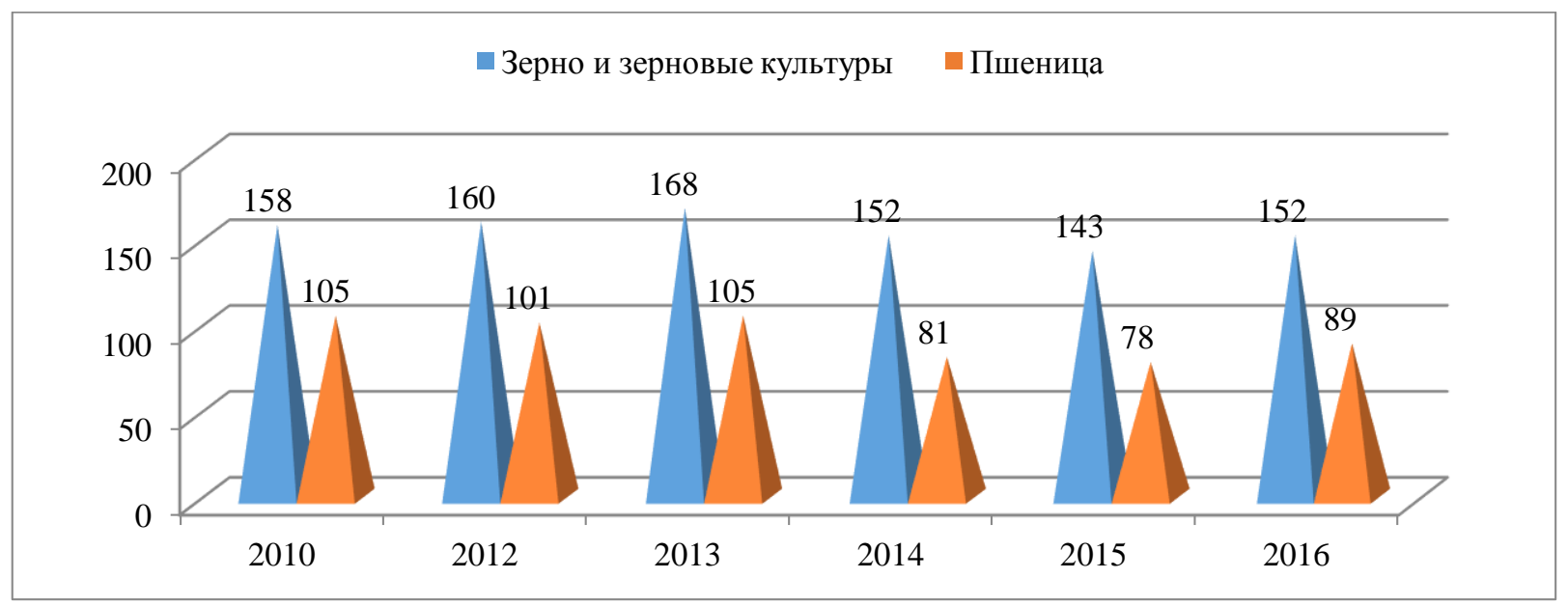

Рисунок 4. Объем пахотных участков по зерну и зерновых культур, в том числе пшеница в регионе

Шеки-Закатала, тыс. га. (подготовлено автором на основе материалов Государственного Статистического Комитета Азербайджанской Республики. www.stat.gov.az).

А на Рисунке 5 отражены показатели объема продукции зерно и зерновых культур, в том числе пшеница в регионе Шеки-Закатала, которое сыграет важную роль в обеспечении стратегической продовольственной продукции зерном население страны. 


\begin{tabular}{|c|c|c|c|c|c|c|}
\hline Impact Factor: & $\begin{array}{l}\text { ISRA (India) } \\
\text { ISI (Dubai, UAE } \\
\text { GIF (Australia) } \\
\text { JIF }\end{array}$ & $\begin{array}{r}=1.344 \\
=0.829 \\
=0.564 \\
=1.500\end{array}$ & $\begin{array}{l}\text { SIS (USA) } \\
\text { PИНЦ (Russia) } \\
\text { ESJI (KZ) } \\
\text { SJIF (Morocco) }\end{array}$ & $\begin{array}{l}=0.912 \\
=0.207 \\
=4.102 \\
=2.031\end{array}$ & $\begin{array}{l}\text { ICV (Poland) } \\
\text { PIF (India) } \\
\text { IBI (India) }\end{array}$ & $\begin{array}{l}=6.630 \\
=1.940 \\
=4.260\end{array}$ \\
\hline
\end{tabular}

\section{— Зерно и зерновые культуры пшеница}

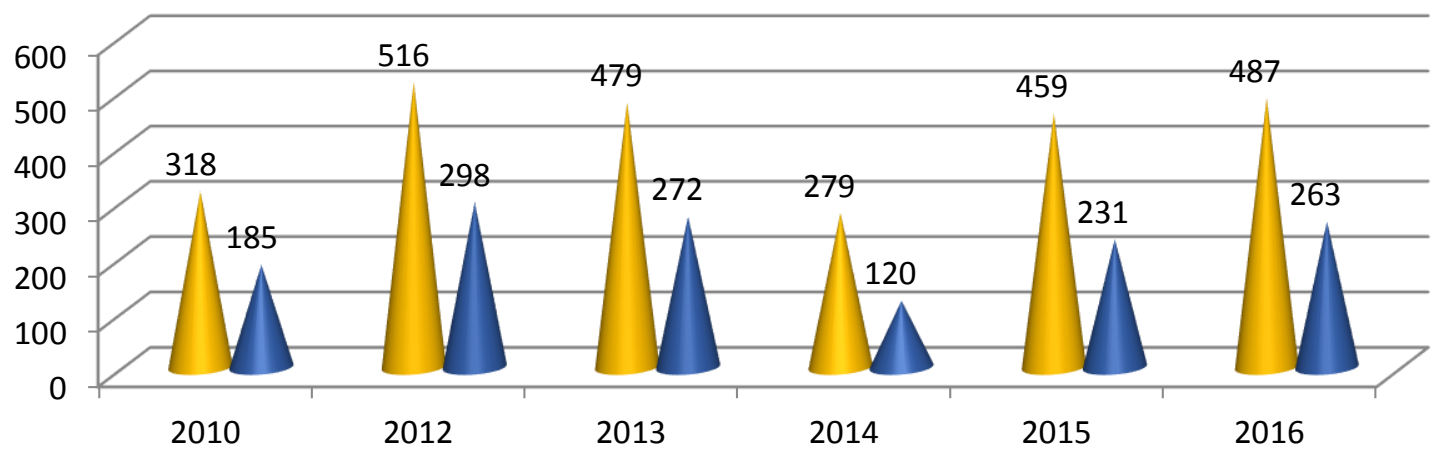

Рисунок 5. Объем продукции зерно и зерновых культур, в том числе пшеница в регионе ШекиЗакатала, тыс. тон (подготовлено автором на основе материалов Государственного Статистического Комитета Азербайджанской Республики. www.stat.gov.az).

На Рисунке 6 отражено показатели по тем видам деятельности, в котором имеется большей потенциал по специализации: объем продукции картофеля, овощей, бахчевых культур, фруктов и ягод в регионе Шеки-Закатала.

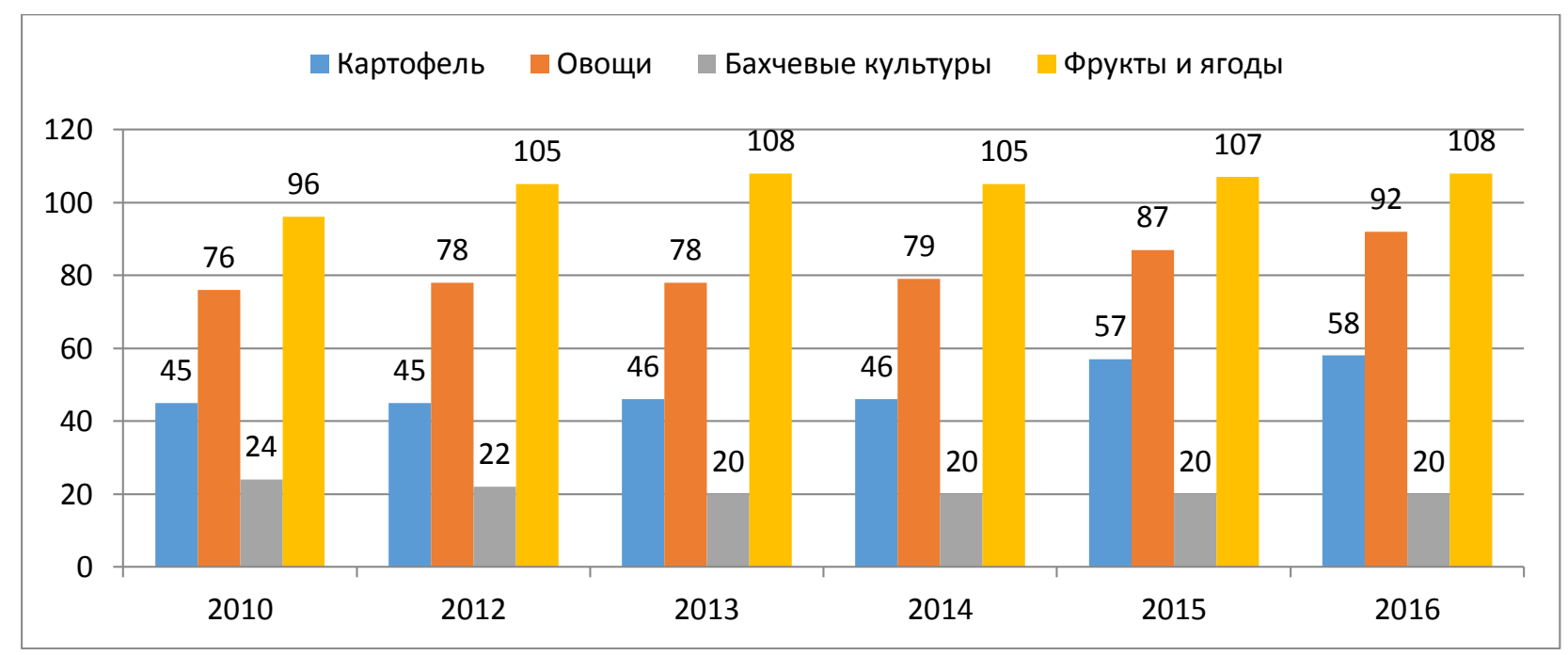

Рисунок 6. Объем продукции картофеля, овощей, бахчевых культур, фруктов и ягод в регионе ШекиЗакатала, тыс. тон (подготовлено автором на основе материалов Государственного Статистического Комитета Азербайджанской Республики. www.stat.gov.az ).

Кроме того, регион имеет реальный потенциал по развитию и увеличению роста производства табака, в том числе расширения деятельности предприятия табаководство.
На Рисунке 7 дано объем производства табака в регионе Шеки-Закатала за 2010-2016 годы. 


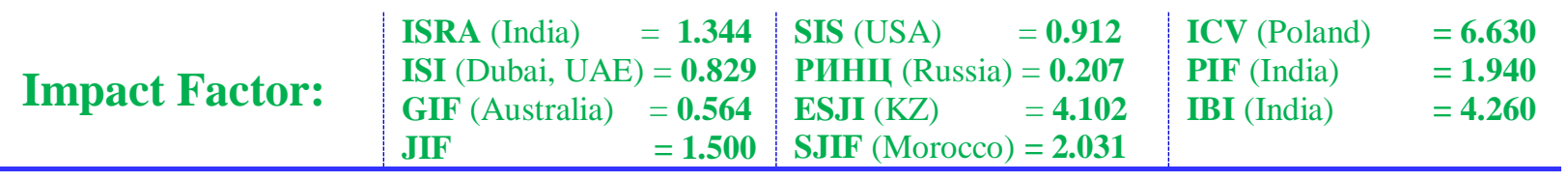

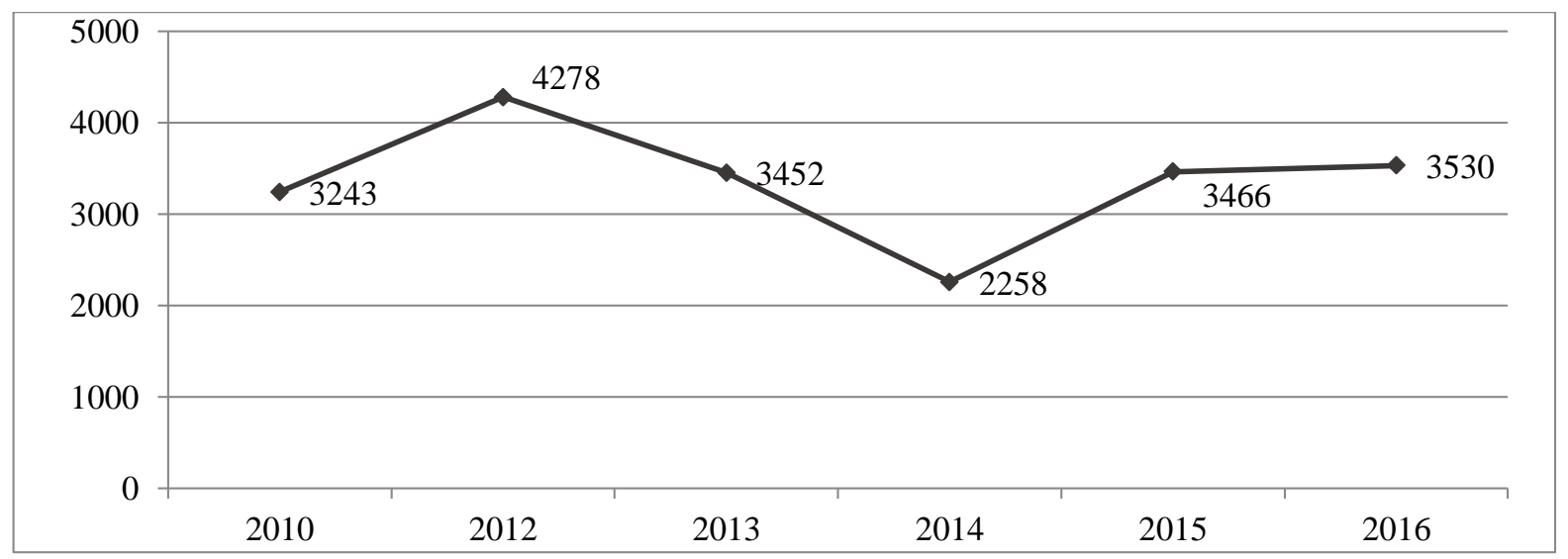

Рисунок 7. Объем производства табака в регионе Шеки-Закатала, тон (подготовлено автором на основе материалов Государственного Статистического Комитета Азербайджанской Республики. www.stat.gov.az).

В экономическом регионе Шеки-Закатала имеется мощный потенциал по развитию ряда древних видов деятельности: животноводство, птицеводство и пчеловодство.
На Рисунке 8 дано численность крупного рогатого скота, в том числе коров и буйволов в регионе Шеки-Закатала, который сыграет огромную роль в занятости и повышения доходов населения.

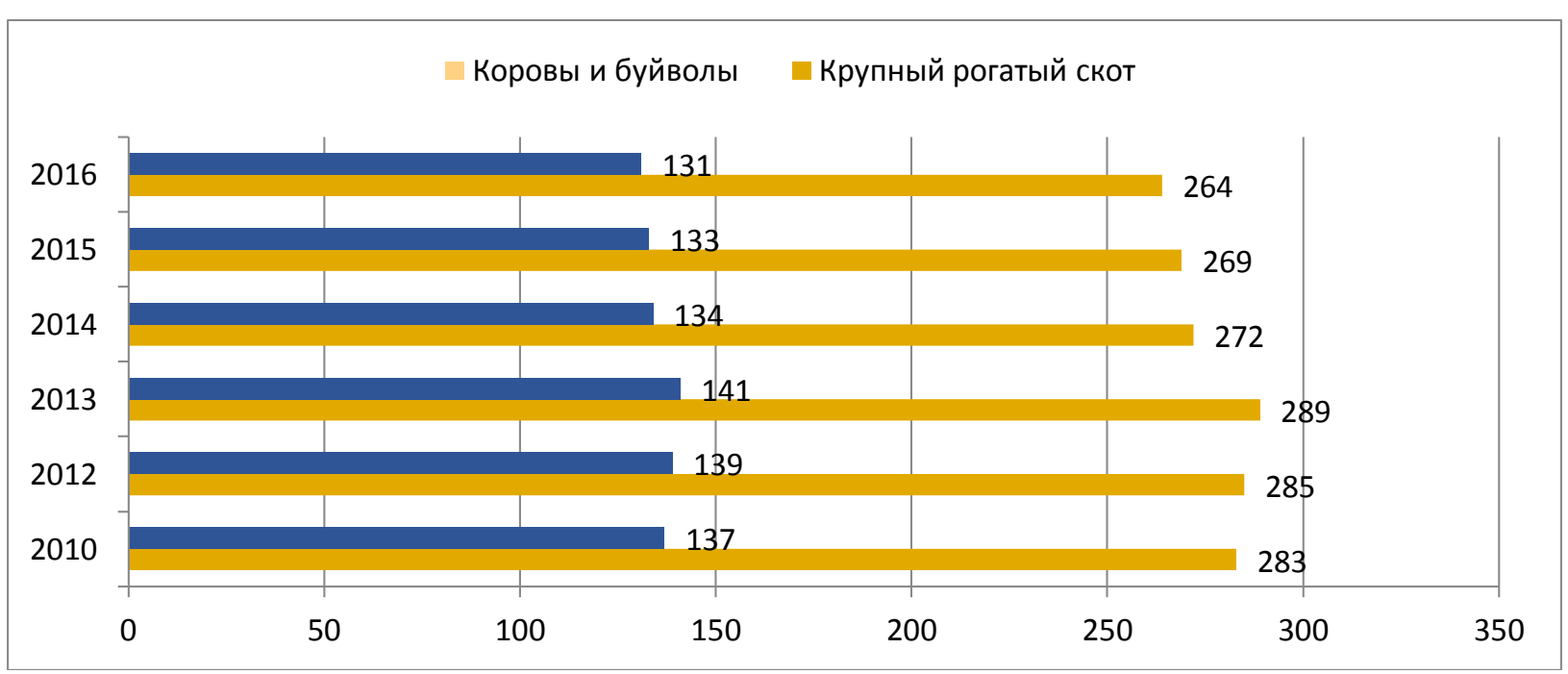

Рисунок 8. Численность крупного рогатого скота, в том числе коров и буйволов в регионе Шеки-

Закатала, тыс. голов (подготовлено автором на основе материалов Государственного Статистического Комитета Азербайджанской Республики. www.stat.gov.az).

А на Рисунке 9 отражено численность овец и коз в регионе Шеки-Закатала за 2010-2016 годы. 


\begin{tabular}{|c|c|c|c|c|c|c|}
\hline Impact Factor: & $\begin{array}{l}\text { ISRA (India) } \\
\text { ISI (Dubai, UAE } \\
\text { GIF (Australia) } \\
\text { JIF }\end{array}$ & $\begin{array}{r}=1.344 \\
=0.829 \\
=0.564 \\
=1.500\end{array}$ & $\begin{array}{l}\text { SIS (USA) } \\
\text { PИНЦ (Russia) } \\
\text { ESJI (KZ) } \\
\text { SJIF (Morocco) }\end{array}$ & $\begin{array}{l}=0.912 \\
=0.207 \\
=4.102 \\
=2.031\end{array}$ & $\begin{array}{l}\text { ICV (Poland) } \\
\text { PIF (India) } \\
\text { IBI (India) }\end{array}$ & $\begin{array}{l}=6.630 \\
=1.940 \\
=4.260\end{array}$ \\
\hline
\end{tabular}

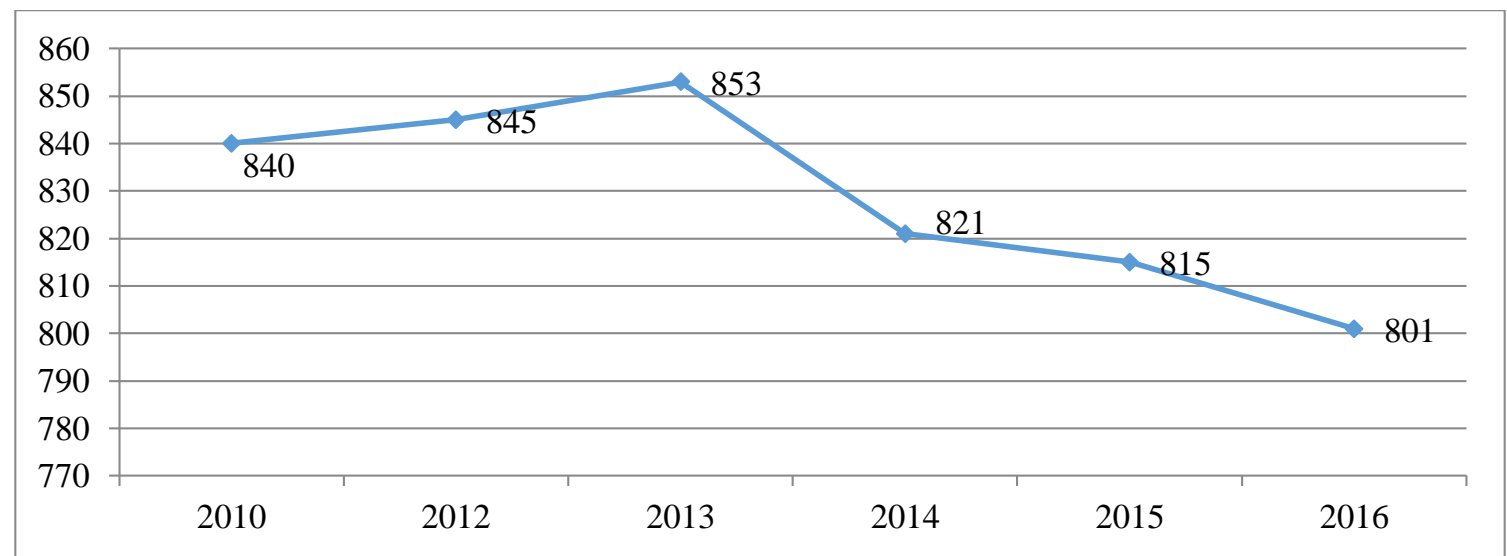

Рисунок 9. Численность овец и коз в регионе Шеки-Закатала, тыс. голов (подготовлено автором на основе материалов Государственного Статистического Комитета Азербайджанской Республики. www.stat.gov.az).

Птицеводство является одним из мощных и перспективных сфер деятельности, который имеет серьезную почву для специализации данной сферы в регионе, однако за последние годы рациональное использование данного потенциала неадекватен и это видно по Рисунку 10.

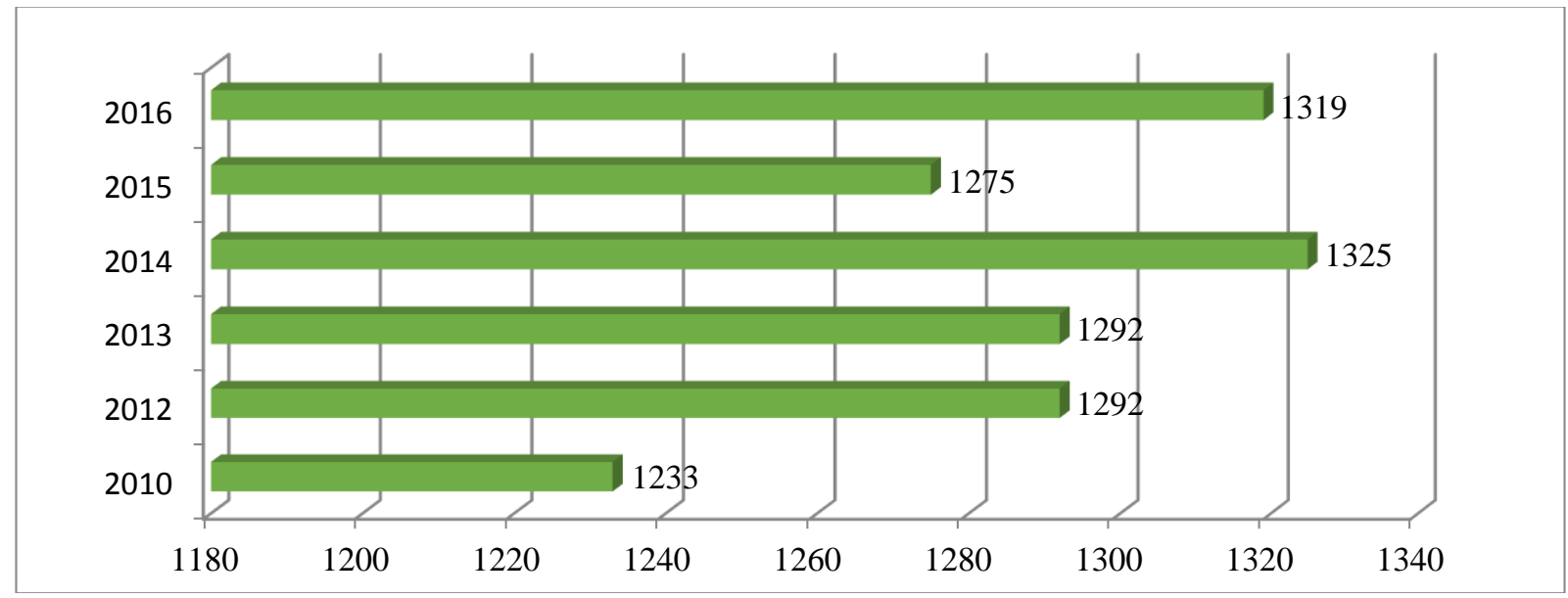

Рисунок 10. Численность птиц в регионе Шеки-Закатала, тыс. голов (подготовлено автором на основе материалов Государственного Статистического Комитета Азербайджанской Республики. www.stat.gov.az).

В регионе концентрировано природные дары и ценности по выращиванию ценнейшего продукта - меда и это обуславливает интенсивного развития пчеловодство в регионе.
Только за 2010-2016 годы число пчельных семейств выросло 37,5 \% и по итогом 2016 года составило 44 тыс. единиц (см. Рисунок 11). 


\begin{tabular}{|c|c|c|c|c|c|c|}
\hline Impact Factor: & $\begin{array}{l}\text { ISRA (India) } \\
\text { ISI (Dubai, UAE } \\
\text { GIF (Australia) } \\
\text { JIF }\end{array}$ & $\begin{array}{r}=1.344 \\
=0.829 \\
=0.564 \\
=1.500\end{array}$ & $\begin{array}{l}\text { SIS (USA) } \\
\text { PИНЦ (Russia) } \\
\text { ESJI (KZ) } \\
\text { SJIF (Morocco) }\end{array}$ & $\begin{array}{l}=0.912 \\
=0.207 \\
=4.102 \\
=2.031\end{array}$ & $\begin{array}{l}\text { ICV (Poland) } \\
\text { PIF (India) } \\
\text { IBI (India) }\end{array}$ & $\begin{array}{l}=6.630 \\
=1.940 \\
=4.260\end{array}$ \\
\hline
\end{tabular}

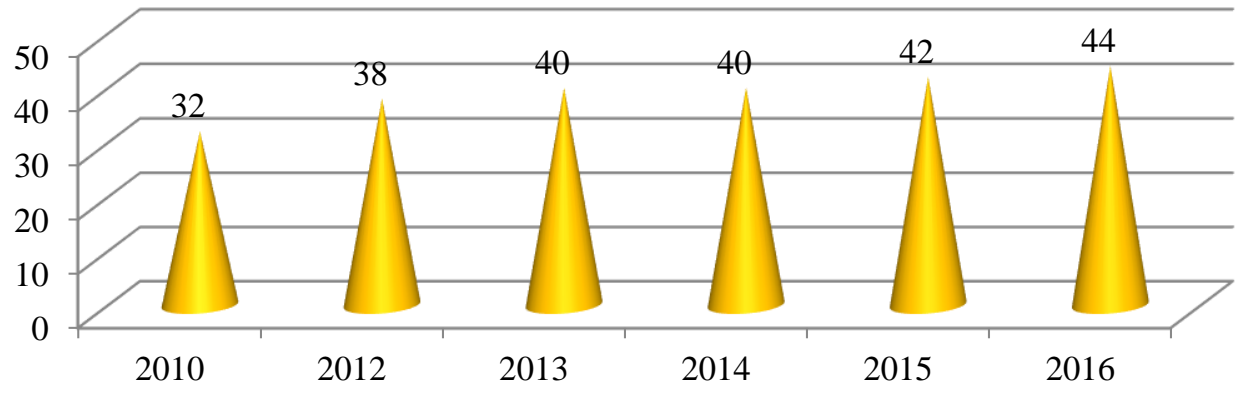

Рисунок 11. Численность пчельных семейств в регионе Шеки-Закатала, тыс. единиц (подготовлено автором на основе материалов Государственного Статистического Комитета Азербайджанской Республики. www.stat.gov.az).

Отметим, что за последние годы проводиться масштабные работы по повышению инвестиционной привлекательности региона Шеки-Закатала и по повышению его экономического потенциала $[15 ; 16 ; 17 ; 18 ; 19 ; 20]$.
На Рисунке 12 дано объем капитальных вложений в регионе Шеки-Закатала в 2010-2016 годы.

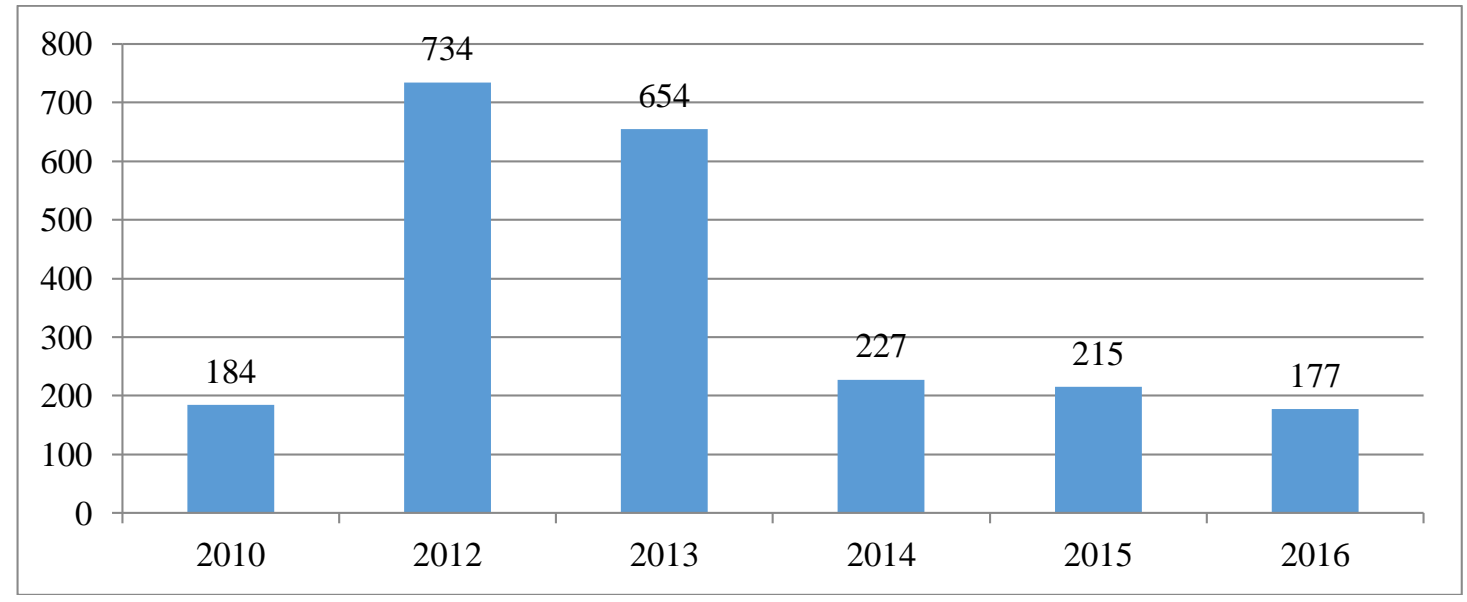

Рисунок 12. Объем капитальных вложений в регионе Шеки-Закатала, млн. манат (подготовлено автором на основе материалов Государственного Статистического Комитета Азербайджанской Республики. www.stat.gov.az).

А на Рисунке 12 дано объем промышленной продукции в регионе Шеки-Закатала за 2010-2016 годы, где рост промышленной продукции составило 3,2 раза и по итогом 2016 года фиксировано на уровне 193 млн. манат. 


\begin{tabular}{|c|c|c|c|c|c|c|}
\hline \multirow{4}{*}{ Impact Factor: } & ISRA (India) & $=1.344$ & SIS (USA) & $=0.912$ & ICV (Poland & $=6.630$ \\
\hline & ISI (Dubai, UAE & $=0.829$ & РИНЦ (Russia) & $=0.207$ & PIF (India) & $=1.940$ \\
\hline & GIF (Australia) & $=0.564$ & ESJI (KZ) & $=4.102$ & IBI (India) & $=4.260$ \\
\hline & JIF & $=1.500$ & SJIF (Morocco & $=2.031$ & & \\
\hline
\end{tabular}

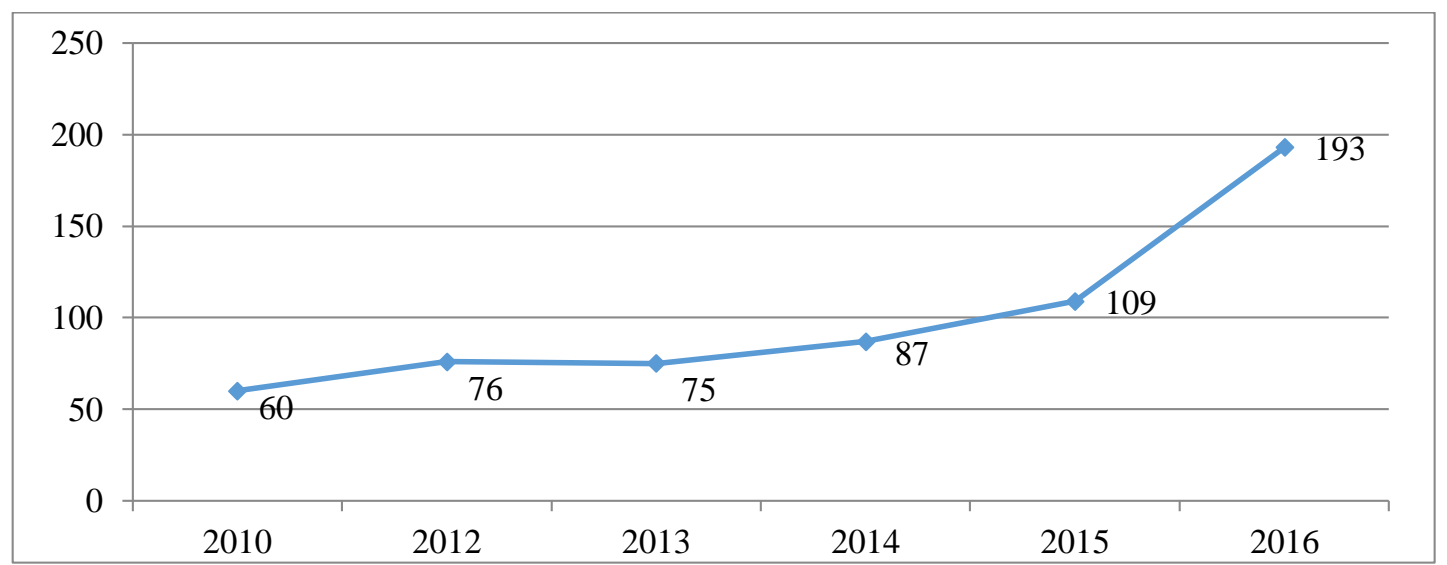

Рисунок 13. Объем промышленной продукции в регионе Шеки-Закатала, млн. манат (подготовлено автором на основе материалов Государственного Статистического Комитета Азербайджанской Республики. www.stat.gov.az).

\section{Conclusion}

Анализы и исследования природного и экономического потенциала региона ШекиЗакатала показывает, что имеются реальные возможности за близлежащей перспективе превратить регион в один из высокоразвитых агроцентров и туристического региона страны. На состояния 01.01.2017-го года в регионе функционировало 46,8 тыс. хозяйственных субъектов, из них 4,5 тыс. юридические лица и 42,3 тыс. физические лица. За 2016 год объем выпускаемой продукции и услуги составило 1,2 млрд. манат. Выработано промышленные продукции на сумму 193,2 млн., а сельскохозяйственные продукции 494,2 млн. манат, в том числе 251 млн. манат - продукции растениеводство и 243,3 млн. манат продукции животноводство [21]. Считаем, что в близлежащем долгосрочном перспективе регион Шеки-Закатала имеет не малые резервы и объективные возможности по специализацию расширения деятельности в сферах сельского хозяйства, агропромышленной и сфере туризма.

\section{References:}

1. (2018) Gosudarstvennaya programma sotsial'no-ekonomicheskogo razvitiya regionov Azerbaydzhanskoy Respubliki v 2014-2018 godakh.

2. (2012) Kontseptsiya Razvitiya Azerbaydzhana - 2020: Vzglyad v Budushcheye. Utverzhdeno Ukazam Prezidenta Azerbaydzhanskoy Respubliki ot 29 dekabrya 2012 goda. Baku, 2012.- 39 p.

3. (2016) Strategicheskiye dorozhnyye karty po natsional'noy ekonomike i osnovnym sektorom ekonomiki. Ukaz Prezidenta Azerbaydzhanskoy Respubliki. Baku, 6 dekabrya 2016 goda.

4. (2016) Strategicheskiye dorozhnyye karty po proizvodstvu i pererabotke produktsii sel'skogo khozyaystva v Azerbaydzhanskoy Respublike. Utverzhdeno Ukazom Prezidenta
Azerbaydzhanskoy Respubliki ot 6 dekabrya 2016 goda. -177 p.

5. (2011) Prioritetnyye napravleniya po sfere ekonomiki i ekonomicheskikh rayonov Azerbaydzhanskoy Respubliki. Utverzhdeno resheniyem zasedaniya Nablyudatel'nogo Soveta Natsional'nogo Fonda Pomoshch' Predprinimatel'stvo Azerbaydzhanskoy respubliki ot 8 maya 2009 goda (protokol №7). Baku, 2011.- 110 p.

6. (2011) Pasport ekonomicheskogo rayona ShekiZakatala. Nauchno-Issledovatel'skiy Institut Ekonomicheskikh Reform Baku, 2011.-81 p.

7. (2017) Ekonomicheskiy rayon Sheki-Zakatala 2017. Ministerstvo Ekonomiki i Promyshlennosti Azerbaydzhanskoy Respubliki. Available: 


\begin{tabular}{l|lr|ll|ll} 
& ISRA (India) & $=\mathbf{1 . 3 4 4}$ & SIS (USA) & $=\mathbf{0 . 9 1 2}$ & ICV (Poland) & $=\mathbf{6 . 6 3 0}$ \\
Impact Factor: & ISI (Dubai, UAE) $=\mathbf{0 . 8 2 9}$ & PUHЦ (Russia) $=\mathbf{0 . 2 0 7}$ & PIF (India) & $=\mathbf{1 . 9 4 0}$ \\
& GIF (Australia) & $\mathbf{0 . 5 6 4}$ & ESJI (KZ) & $=4.102$ & IBI (India) & $=\mathbf{4 . 2 6 0}$ \\
& JIF & $=\mathbf{1 . 5 0 0}$ & SJIF (Morocco) & $=\mathbf{2 . 0 3 1}$ & & \\
\hline
\end{tabular}

http://www.economy.gov.az/article/histry-ofministry/21256. (Accessed: 10.03.2018).

8. (2018) Ekonomicheskiy rayon Sheki-Zakatala. Available: $\quad$ http://www.wikivisually.com. (Accessed: 10.03.2018).

9. (2018) Ekonomicheskiy rayon Sheki-Zakatala: tselevyye podkhody. Available: http://www.biznesinfo.az. $\quad$ (Accessed: 10.03.2018).

10. (2018) Provedeno seminar po teme perspektivy razvitiya turizma $\mathrm{v}$ ekonomicheskom rayone Sheki-Zakatala.

Available: http://www.old.525.az. (Accessed: 10.03.2018).

11. Shal'buzov N., Guseynov R. (2018) Odnoy iz prioritetov Strategicheskikh Dorozhnykh kart: razvitiya zerno i zernovykh kul'tur. Available: http://iqtisadiislahat.org(Accessed: 10.03.2018).

12. (2018) Ekonomiko-geograficheskiy rayon Sheki-Zakatala.

Available: http://gsaz.az/articles/view/112/ShakiZaqatalaiqtisadicografi-rayonu. (Accessed: 10.03.2018).

13. Gadzhizade E. (2018) Regional'nyy analiz ekonomiki Azerbaydzhana. https://elsenbagirzade.files.wordpress.com. (Accessed: 10.03.2018).

14. (2018) Obespechivayetsya razvitiye tabakovodstvo i sadovodstvo v Zagatalinskom rayone.

Available: http://www.economy.gov.az. $\quad$ (Accessed: 10.03.2018).
15. (2018) Potentsial Azerbaydzhana po proizvodstvu sigareta iz mestnogo tabaka bol'shaya.

http://pia.az/m/news.php?id=233770\#.Wr_AGS 5uaUk. (Accessed: 10.03.2018).

16. (2017) Investitsionnyy reyting rayonov. Tsentr Analiza Ekonomicheskikh Reform i Kommunikatsii. Baku, 19 aprelya 2017 god- 8 p. Available: http://ecoreform.az (Accessed: 10.03.2018).

17. Mamedov S. (2018) Razvitiya promyshlennosti fundukovodstvo pereshel na novyy etap. Available:

http://www.xalqqazeti.com/az/news/economy/8 9882(Accessed: 10.03.2018).

18. (2017) Ekonomicheskiye zony Sheki-Zakatala podpisano proyekt podderzhki razvitiya malykh semeynykh predpriyatiy. 13 dekabrya 2017 goda. Available: http://newscenter.az. (Accessed: 10.03.2018).

19. (2018) Kredity i sberezheniye $\mathrm{v}$ regionakh. Available: http://www.novator.az. (Accessed: 10.03.2018).

20. (2018) Ob"yem vydelennogo l'gotnogo kredita v ekonomicheskom rayone Sheki-Zakatala dostigla 100 mln. manat. Available: http://www.gomap.az/info/Detailed_News.aspx ?id=41367. (Accessed: 10.03.2018).

21. (2017) Regiony Azerbay dzhana. Statisticheskoye zdaniye. Baku, 2017.- 806 p. 